\title{
Association between ABO blood types and coronavirus disease 2019 (COVID-19), genetic associations, and underlying molecular mechanisms: a literature review of 23 studies
}

\author{
Yujia Zhang $^{1} \cdot$ Rachael Garner $^{1} \cdot$ Sana Salehi $^{2} \cdot$ Marianna La Rocca $^{1} \cdot$ Dominique Duncan $^{1}$ \\ Received: 30 December 2020 / Accepted: 2 March 2021 / Published online: 8 March 2021 \\ (C) The Author(s), under exclusive licence to Springer-Verlag GmbH Germany, part of Springer Nature 2021
}

\begin{abstract}
An association of various blood types and the 2019 novel coronavirus disease (COVID-19) has been found in a number of publications. The aim of this literature review is to summarize key findings related to ABO blood types and COVID-19 infection rate, symptom presentation, and outcome. Summarized findings include associations between ABO blood type and higher infection susceptibility, intubation duration, and severe outcomes, including death. The literature suggests that blood type $\mathrm{O}$ may serve as a protective factor, as individuals with blood type $\mathrm{O}$ are found COVID-19 positive at far lower rates. This could suggest that blood type $\mathrm{O}$ individuals are less susceptible to infection, or that they are asymptomatic at higher rates and therefore do not seek out testing. We also discuss genetic associations and potential molecular mechanisms that drive the relationship between blood type and COVID-19. Studies have found a strong association between a locus on a specific gene cluster on chromosome three (chr3p21.31) and outcome severity, such as respiratory failure. Cellular models have suggested an explanation for blood type modulation of infection, evidencing that spike protein/Angiotensin-converting enzyme 2 (ACE2)-dependent adhesion to ACE2-expressing cell lines was specifically inhibited by monoclonal or natural human anti-A antibodies, so individuals with non-A blood types, specifically $\mathrm{O}$, or B blood types, which produce anti-A antibodies, may be less susceptible to severe acute respiratory syndrome coronavirus 2 (SARS-CoV-2) infection due to the inhibitory effects of anti-A antibodies.
\end{abstract}

Keywords COVID-19 · Coronavirus · 2019-nCoV · ABO blood types $\cdot$ SARS-CoV-2

Yujia Zhang

zhan834@usc.edu

Rachael Garner

Rachael.Garner@loni.usc.edu

Sana Salehi

ss_633@usc.edu

Marianna La Rocca

marianna.larocca@loni.usc.edu

Dominique Duncan

duncand@usc.edu

1 Laboratory of Neuro Imaging, USC Stevens Neuroimaging and Informatics Institute, Keck School of Medicine of USC, University of Southern California, 2025 Zonal Ave., Los Angeles, CA 90033, USA

2 Department of Radiology, Keck School of Medicine of USC, University of Southern California, 1500 San Pablo St., Los Angeles, CA 90033, USA

\section{Introduction}

\section{COVID-19 pandemic}

The World Health Organization (WHO) received several reports of unidentified pneumonia from Wuhan, China on December 31, 2019. On January 7, 2020, the cause of those reported cases was found to be the 2019 novel coronavirus (2019-nCoV). The disease was later named severe acute respiratory syndrome coronavirus 2 (SARS-CoV-2) and coronavirus disease 2019 (COVID-19). The WHO declared the outbreak a global health emergency on January 30, 2020 [1].

COVID-19 has become a global concern because it spreads easily and quickly through close contact. The main transmission mechanism is via respiratory droplets containing infectious virus particles. These droplets are transmitted during breathing, coughing, sneezing, and speaking. Airborne transmission and contact transmission are also potential vectors of infection.

Symptoms present following the incubation period, which can be 2-14 days after exposure to the virus. People infected 
with COVID-19 may have mild to severe symptoms. Common mild symptoms are dry cough, fever, and fatigue. In severe cases, individuals experience acute respiratory distress syndrome, septic shock, or death [2].

Mortality varies from country to country: currently, the highest mortality is around $8.9 \%$ in Mexico, and the lowest is around $0.9 \%$ in Turkey [3]. As of December 21, 2020, there are $77,202,828$ cases and 1,639,709 deaths worldwide due to COVID-19 infection [3]. Managing the spread of this pandemic is very challenging because individuals are contagious during the incubation period [2]. Moreover, new research has found that $10-30 \%$ of people are asymptomatically infected with 2019$\mathrm{nCoV}$ and readily become a conduit for viral transmission [4].

\section{Defining risk factors}

In general, risk factors are variables associated with an increased risk of disease or infection [5]. There are two types of risk factors: nonmodifiable risk factors and modifiable risk factors [6]. A conclusive panel of risk factors for COVID-19 infection susceptibility and prognosis is still being explored; however, several risk factors have been proposed.

Nonmodified risk factors for COVID-19 infection are innate traits. Black and Hispanic heritage were found to be risk factors for testing positive for COVID-19, but not for 30-day mortality in a retrospective cohort study of nearly 6 million individuals seeking care from the US Department of Veteran Affairs [7]. Age over 65 has also been reported as a risk factor for severe outcome, potentially due to increased comorbidities prevalent with age, and decreased efficacy of the immune system, including delayed macrophage function and reduced $\mathrm{T}$ cell propagation [8].

Modifiable risk factors can be controlled, manipulated, or treated through intervention or lifestyle changes. Several meta-analyses have reported that tobacco smokers may be susceptible to increased COVID-19 severity compared with nonsmokers [9-11], including increased Intensive Care Unit (ICU) support, mechanical ventilation, and death [12]. However, some studies have also reported non-significant relationships between smoking and COVID-19 severity [13].

Identifying consistent risk factors is critical to ensure that those at higher risk of infection can take added precautions to prevent acquiring the infection. Additionally, understanding those who are at greatest risk for severe prognosis or death may help clinicians better predict patient outcome, allowing for more targeted allocation of limited critical care resources during epidemic surges.

\section{Blood type as a non-modifiable risk factor}

ABO blood type is an inherited, non-modifiable trait. Individuals can be $\mathrm{A}, \mathrm{B}, \mathrm{AB}$, or $\mathrm{O}$ depending on the antigens present or absent on erythrocyte surfaces. Blood types may also be characterized as positive or negative depending on the presence of the Rhesus $(\mathrm{Rh})$ factor protein. Numerous studies have previously found associations between $\mathrm{ABO}$ blood types and viral respiratory infections such as influenza A (H1N1) and acute respiratory syndrome (SARS) [14-16]. Recently, several studies have proposed relationships between blood types and susceptibility to COVID-19, its significance in the course of the disease, and outcomes [17-25].

\section{Motivations and study aims}

The aim of this work is to summarize the key findings of published studies on this topic to identify the relationship between blood type, COVID-19 infection rates, and outcomes, as well as the role of genetics and the underlying molecular mechanism responsible for susceptibility and severity. Although the relationship between blood type, COVID-19 infection, and severe outcome is still under debate, it is critical to understand the potential risk factor's influence to allow relevant individuals to take added precautions to prevent acquiring the infection.

\section{Methodology}

A comprehensive online literature search was conducted using the keywords "COVID-19," "2019-nCoV," "SARS-CoV-2," "ABO blood types," and "blood group" on PubMed, Embase (Elsevier), and Google Scholar. The identified studies were screened by title and abstracts by two independent reviewers (authors YZ and SS). After discussing the disagreements, the authors reached a consensus to include 23 studies, all published in English, for the final review. The initial data extraction, including study design, number of patients, selection criteria, limitations, and major findings, was carried out by one of the authors (YZ) and assessed for accuracy by other authors (RG, SS, MLR, and DD). We note that this study was primarily designed as a narrative literature review, hence does not entirely follow the Preferred Reporting Items for Systematic Reviews (PRISMA) [26] method which is designed for systematic reviews/meta-analysis.

\section{Association between ABO blood groups and viral respiratory infections}

The role of blood types in bacterial and viral infections has always been an area of interest among researchers in the field [27]. The association between blood types and different viral respiratory diseases such as H1N1 and severe acute respiratory syndrome (SARS) has been previously discussed in multiple publications [14-16]. SARS, similar to COVID-19, is also caused by a member of Coronaviridae family known as SARS-associated coronavirus (SARS-CoV). 


\section{Blood types related to severe acute respiratory syndrome infection}

In 2003, several unidentified pneumonia cases were reported in Asia, and later, the illness was confirmed to be caused by a coronavirus named SARS-associated coronavirus (SARS$\mathrm{CoV}$ ). This severe respiratory disease was named severe acute respiratory syndrome (SARS). Soon, SARS spread globally, including to North and South America, Europe, and Asia [28]. Researchers later found an association between blood type and SARS: individuals with blood type $\mathrm{O}$ were less likely to become infected with SARS compared with non-blood type $\mathrm{O}$ individuals [14].

\section{Blood types related to influenza infection}

Influenza is a common viral infection caused by the influenza virus. Type $A$ and Type $B$ are the two main types of influenza viruses. The flu is a contagious respiratory disease that can cause mild to severe illness, with common symptoms including fever, cough, and sore throat. Flu viruses can be easily spread by droplets that are transmitted when people talk, cough, or sneeze [29]. Studies have shown an association between flu infection and blood type. During the outbreak of flu caused by H1N1, a subtype of Type A influenza virus, patients with blood group $\mathrm{A}$ and $\mathrm{B}$ were more susceptible to infection than those with blood group $\mathrm{O}$ and $\mathrm{AB}$ [15]. Similarly, researchers found that individuals with blood group B were more susceptible to infection by $\mathrm{H} 3 \mathrm{~N} 2$, a Type A influenza subtype [16].

\section{Association between ABO blood type and COVID-19}

In order to review evidence of associations between $\mathrm{ABO}$ blood types and COVID-19 infection, 23 literature papers were studied. Summarized findings include the associations between blood type and higher infection susceptibility, severe outcomes, and death, as well as genetic association and potential molecular mechanisms that drive the relationship between blood type and COVID-19 infection.

\section{Association of blood type with higher susceptibility of testing positive}

Recent studies have shown that blood type A is associated with the highest probability of SARS-CoV-2 infection [17-21]. A summary of findings is reported in Table 1. One of the earliest studies in Wuhan, China, suggested that there was an association between blood type A and COVID-19, noting that females with blood type A were more susceptible to infection [17]. Subsequent studies also reported that blood type A patients had significantly higher odds of acquiring SARS-CoV-2 infection compared with non-A blood types [18-20].

Several studies have also reported that blood type O patients have significantly lower odds of infection, suggesting that blood type $\mathrm{O}$ may be a protective factor against infection [18-20, 22, 23].

In one multivariate analysis of 14,112 patients who tested positive for COVID-19 in the New York Presbyterian hospital system, investigators reported that blood type $\mathrm{A}, \mathrm{AB}$, and $\mathrm{B}$ had higher prevalence than blood type $\mathrm{O}$ after adjusting for race and ethnicity [24]. A retrospective study at the First Hospital of Changsha in Changsha, Hunan, China, similarly showed that blood type is a strong risk factor for COVID-19. Blood type $\mathrm{O}$ patients had decreased risk of infection compared with non-O blood group patients and blood type A patients had higher risk than all other groups [21].

While the literature generally agrees that blood type $\mathrm{O}$ is a protective factor [22], there is disagreement on which blood type has the highest susceptibility. Contrary to studies citing blood type A as the most at-risk group, several studies have suggested high risk for blood type $\mathrm{B}$ and $\mathrm{AB}$ [23]. One of the largest retrospective cohort studies indicated that risk ratios associated with SARS-CoV-2 infection were 0.87, 1.09, 1.06 , and 1.15 for $\mathrm{O}, \mathrm{A}, \mathrm{B}$, and $\mathrm{AB}$ individuals, respectively. Risk ratio compares the risk of health event among one group with another group. If the risk ratio equals to 1 , it indicates the identical risk among two groups. A risk ratio is greater than 1, which means the group in the numerator is the exposed group. The risk ratio is smaller than 1 ; it indicates that the exposed group has lower risk and may play a protective role [32]. Padhi et al. [25] also reported that blood type B and AB were associated with higher odds of testing positive for SARSCoV-2 infection, whereas blood type $\mathrm{O}$ was associated with lower odds of testing positive. However, the authors found no correlation between blood type A and positive test rates.

\section{ABO blood type and COVID-19 clinical outcomes of severity}

Scientists found that $\mathrm{ABO}$ group is associated not only with COVID-19 infection rates but also with severe outcomes, such as requiring mechanical ventilation or death (Table 2). Literature regarding which blood type is most at risk of severe outcome are more variable than the literature regarding risk of infection.

For example, blood type $\mathrm{O}$ is regarded as a protective factor for infection, but it may not decrease risk of severe outcome. In a study conducted by Zietz et al. [24], blood type A patients had lower risk of intubation and death compared with blood type $\mathrm{O}$ patients, whereas blood type $\mathrm{AB}$ had higher risk of intubation and death. Moreover, individuals with blood type B had higher rates of intubation, but lower mortality compared 


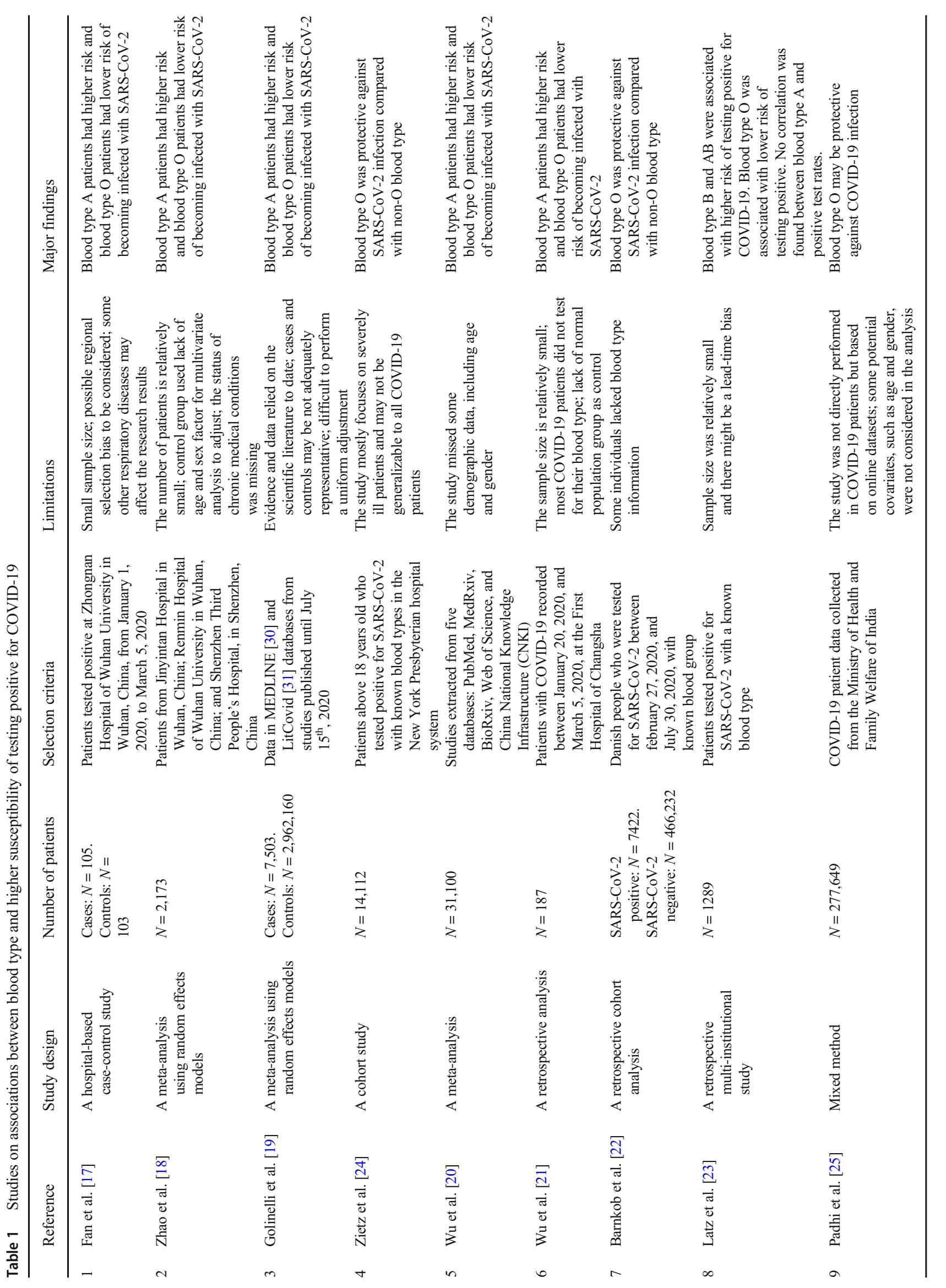




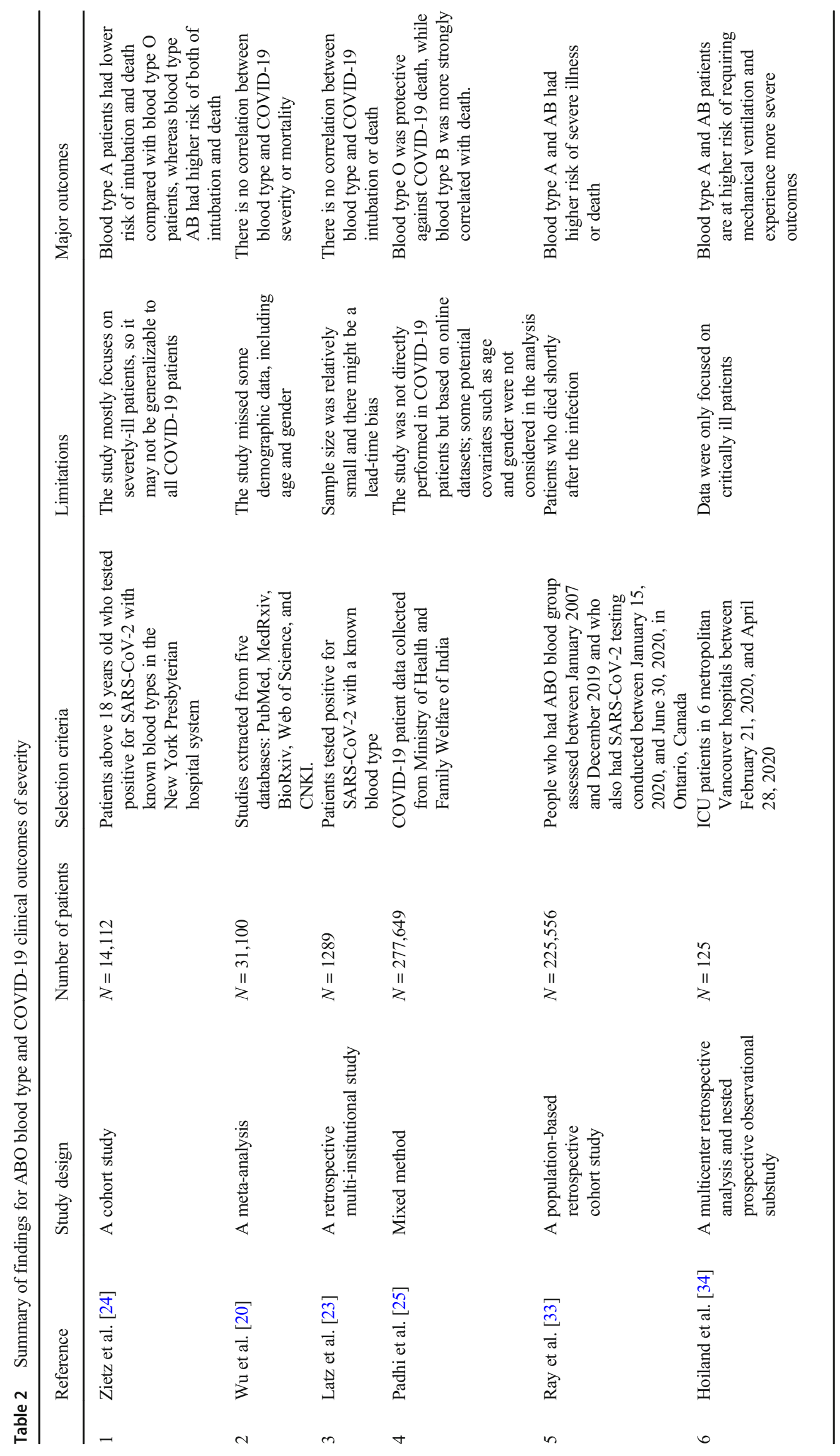


to individuals with blood type O. Conversely, a populationbased cohort study conducted in Ontario, Canada, reported that blood type $\mathrm{O}$ individuals have lower risk of developing severe conditions or death compared with all other blood types [23]. Similarly, in a study conducted using Spearman's rank coefficient analysis on COVID-19 patients collected from the Ministry of Health and Family Welfare in India, scientists found that blood type $\mathrm{O}$ was protective against COVID-19 death and that blood type B was more strongly correlated with infection and death [25].

In contrast, Latz et al. [23] proposed that blood type A had highest risk of intubation and death. Similarly, a multicenter retrospective analysis showed that patients with blood type A or $\mathrm{AB}$ were at higher risk of requiring mechanical ventilation when compared with blood type $\mathrm{O}$ or B patients after adjusting for sex, age, and other factors. Blood type A (12\% of cohort) and $\mathrm{AB}$ patients (32\% of cohort) also had higher probability of requiring continuous renal replacement therapy compared with blood type $\mathrm{O}$ or B patients after adjusting for sex, age, and other factors. After adjustments, there were no differences in median length of ICU stay or probability of ICU discharge or extubation. There was also no association between blood type and death [34].

\section{Association of Rhesus factor with susceptibility to COVID-19 infection and outcomes}

As blood types can be characterized as positive or negative depending on the presence of the Rhesus (Rh) factor protein, it is also significant for researchers to investigate the association between Rh and COVID-19 infection (Table 3).

A study conducted by Latz et al. [23] reported that $\mathrm{Rh}(+)$ was associated with higher odds of testing positive and higher risks of intubation and death. Another study conducted by Zietz et al. [24] showed that $\mathrm{Rh}(-)$ patients had a $2.7 \%$ lower risk of initial infection, intubation, and death after adjusting for sex, age, and other demographics. A study conducted by Ray et al. [33] similarly indicated that individuals with $\mathrm{Rh}(-)$ blood type were less susceptible to infection by SARS-CoV-2, especially individuals with O-negative blood type.

However, another hematological study conducted in Sudan proposed that the O-positive blood group has the lowest risk of having severe symptoms, while the authors agreed that Apositive individuals were the most vulnerable when exposed to the virus [35].

\section{Genetic associations with susceptibility and severity}

$\mathrm{ABO}$ blood type is determined by the $\mathrm{ABO}$ gene, located on the $9^{\text {th }}$ chromosome. It consists of 7 exons and codes for enzyme glycosyltransferases, which is responsible for the formation of antigens in blood type A and/or B [34].
In a meta-analysis, investigators sampled 1980 patients with COVID-19-related respiratory failure at seven centers in Italy and Spain and analyzed 8,582,968 single-nucleotide polymorphisms (SNPs). Researchers reported a crossreplicating association with rs 11385942 at locus 3 p21.31 and with rs657152 at locus 9q34. They found that the 3 p21.31 gene cluster is a genetically susceptibility locus in COVID-19 patients with respiratory failure [36]. Another study conducted by Shelton et al. [37] using trans-ethnic genome-wide association studies similarly reported a strong association between blood type and COVID-19. In particular, there was strong association at a locus on chr3p21.31 with outcome severity [37].

\section{Underlying molecular mechanism of susceptibility and severity of ABO blood types}

Several researchers have proposed potential molecular mechanisms underlying the susceptibility of particular $\mathrm{ABO}$ blood types to COVID-19. A review conducted by Silva-Filho et al. [38] proposed that the association between ABO blood type and COVID-19 susceptibility and infection progression may be related to the varied distribution of sialic acid-containing receptors on host cells' surfaces. This distribution is modulated by $\mathrm{ABO}$ antigens through carbohydrate-carbohydrate interactions (CCIs), which could maximize or minimize the binding capacity of the virus's spike protein, the structural glycoprotein that protrudes from the viral envelope, to host cell's surface receptors. Viral entry is facilitated by interaction of two subunits, S1 and S2. S1 specifically contributes to viral binding to host cell surface receptors via two domains: S1A, corresponding to the N-terminal region, which interacts with sialic-acid containing glycoproteins and glycolipids, and $\mathrm{S} 1 \mathrm{~B}$, corresponding to the receptor-binding domain, which binds to Angiotensin-Convertor Enzyme 2 (ACE2) receptors. ACE2 is the central entry route for several coronaviruses into host cells [39].

$\mathrm{ABH}$ antigens are present on the erythrocyte membrane as well as many other cells, including lymphocytes, platelets, and arterial and venular capillary endothelium [40]. Antigen A especially, but also antigens $\mathrm{AB}$ and $\mathrm{B}$, stimulate carbohydrate clustering, whereas $\mathrm{H}$, the antigen characteristic of $\mathrm{O}$ blood type, does not induce carbohydrate promotion. Additional carbohydrate clustering facilitates CCIs, maximizing interaction, cell recognition, and aggregation [38, 41]. Increased interaction increases the probability of SARSCoV-2 successfully binding to host cells via specific binding of spike protein domains to ACE2 and CD147, a transmembrane protein that may also facilitate the infectious process via viral anchoring to host cells [38]. 


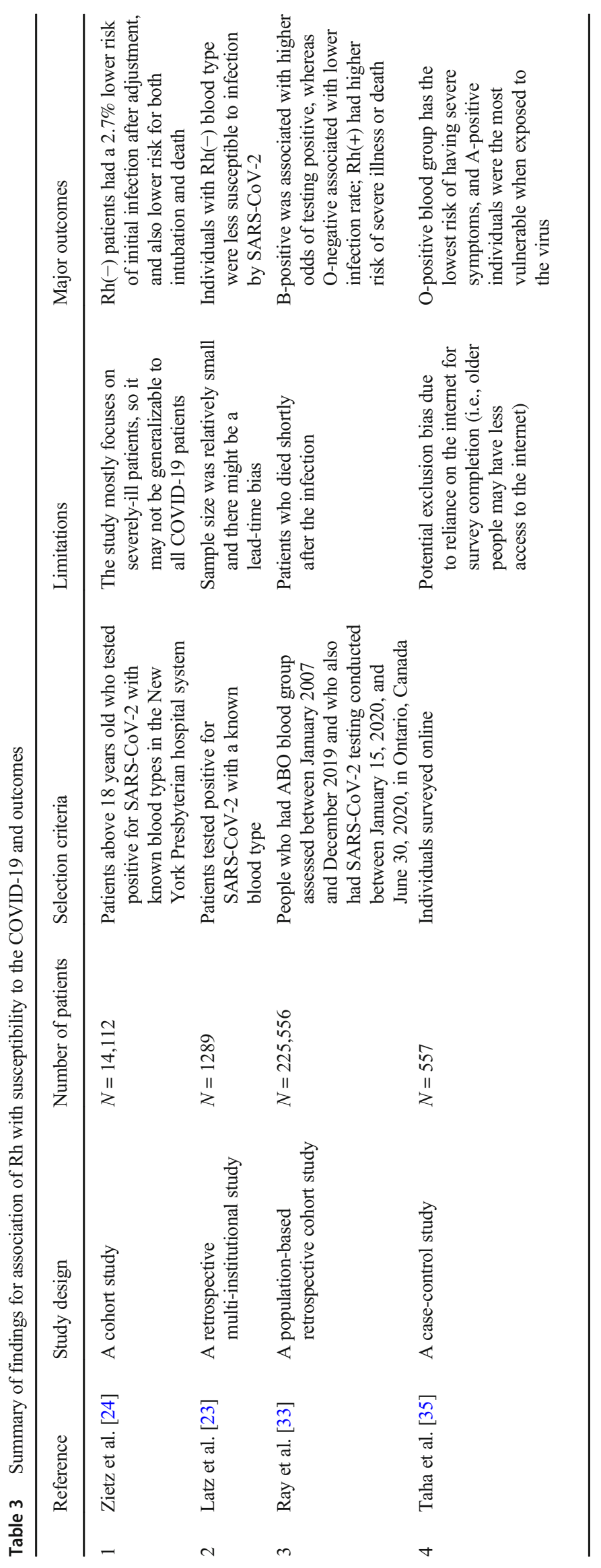


Similar work conducted on SARS-CoV proposed that natural anti-A antibodies may play a role in modulating interaction between the virus and host cells. In the cellular model, spike protein/ACE2-dependent adhesion to ACE2-expressing cell lines was specifically inhibited by monoclonal or natural human anti-A antibodies. Thus, individuals with non-A blood types, specifically $\mathrm{O}$ or B blood type, which produce anti-A antibodies, may be less susceptible to SARS-CoV-2 infection due to the inhibitory effects of anti-A antibodies [42].

Several studies have also suggested that host transmembrane protease serine subtype 2 (TMPRSS2) may play a significant role in ABO group modulation of infection [43, 44]. TMPRSS2 is a gene located on human chromosome 21q22.3 [45], and has been found to be essential for spike protein priming and subsequent infection of SARS-CoV [44]. However, it has not been confirmed if SARS-CoV and SARS-CoV-2 share identical genomic sequences for the serine protease. Despite this, proteolysis of viral serine by TMPRSS2 may allow for serine mobilization, a key molecule in mucin O-glycan that has been found to be critical for infection [44]. Following hybridization to yield O- $N$-acetyl-D-galactosamine (O-GalNAc), SARS-CoV-2 may evade innate or specific immunity by hybridizing $\mathrm{ABO}$ blood group, effectively mimicking self-cell presentation. $\mathrm{A}, \mathrm{B}$, and $\mathrm{AB}$ blood groups have upregulated immunoglobulin $\mathrm{M}$ (IgM) activity, while O-group has downregulated IgM activity due to glycosylation. The A, B, and $\mathrm{AB}$ blood groups are thus preferential targets because they possess $\mathrm{A} / \mathrm{B}$ phenotypic-determining enzymes which facilitate greater viral molecular contact, whereas $\mathrm{O}$ blood type lacks these enzymes and only binds the virus via hybrid H-type antigen formation. Additionally, IgM downregulation in the $\mathrm{O}$ blood group leads to downstream anti-A and anti-B isoagglutinin activity, hallmarks of innate immune activity [43]. Arend et al. [43] and Wang et al. [46] proposed TMPRSS2 inhibition as a potential therapeutic target.

\section{Conclusion}

This review examined published empirical papers and metaanalyses related to the relationship between blood type and COVID-19. These studies suggest that blood type may be a risk factor for COVID-19 infection and outcome. Findings related to the highest risk of infection varied among researchers. The majority of researchers report that the greatest risk for susceptibility to COVID-19 infection is among individuals with blood type $\mathrm{A}$, while some others report that individuals with blood type $\mathrm{B}$ are the most vulnerable group to infection. Although some researchers report that there is no correlation between blood type and COVID-19 severity or mortality, most studies found that blood types $\mathrm{A}$ and $\mathrm{AB}$ had higher risk of severe illness or death, while blood type
$\mathrm{O}$ was protective against death or severe outcomes. Genetic association and several potential mechanisms related to the relationship among blood types $\mathrm{A} / \mathrm{B}$, infection susceptibility, and severe outcome were also reported. It has been found that the $3 p 21.31$ gene cluster is a genetically susceptibility locus in COVID-19 patients with respiratory failure. In the cellular model, ACE2 is an entry for virus into host cell. Spike protein/ACE2-dependent adhesion to ACE2-expressing cell lines was specifically inhibited by monoclonal or natural human anti-A antibodies. Thus, in individuals with non-A blood types, specifically $\mathrm{O}$ or B blood type, anti-A antibodies may play a protective role in SARS-CoV-2 infection due to its inhibitory effects. Moreover, A, B, and AB blood groups are preferential targets compared to $\mathrm{O}$ blood group because they possess $\mathrm{A} / \mathrm{B}$ phenotypic-determining enzymes which facilitate greater viral molecular contact; however, blood type $\mathrm{O}$ lacks these enzymes and only binds the virus via hybrid $\mathrm{H}$ type antigen formation.

Funding This work was supported by the National Science Foundation under Award Number 2027456 (COVID-ARC).

\section{Declarations}

Ethics approval Not applicable.

Consent to participate Not applicable.

Consent for publication Not applicable.

Code availability Not applicable.

Competing interests The authors declare no competing interests.

\section{References}

1. Salehi S, Abedi A, Balakrishnan S, Gholamrezanezhad A (2020) Coronavirus disease 2019 (COVID-19): a systematic review of imaging findings in 919 patients. AJR Am J Roentgenol 215(1): 87-93. https://doi.org/10.2214/AJR.20.23034

2. COVID-19 (Coronavirus Disease). Centers for disease control and prevention. https://www.cdc.gov/coronavirus/2019-ncov/faq.html\# Spread. Accessed November 16, 2020

3. Johns Hopkins University \& Medicine, Coronavirus Resource Center. https://coronavirus.jhu.edu/data/mortality. Accessed December 21, 2020

4. Yu C, Zhou M, Liu Y, Guo T, Ou C, Yang L, Li Y, Li D, Hu X, Shuai L, Wang B, Zou Z (2020) Characteristics of asymptomatic COVID-19 infection and progression: a multicenter, retrospective study. Virulence. 11(1):1006-1014. https://doi.org/10.1080/ 21505594.2020.1802194

5. Parritz RH, Troy MF (2018) Disorders of childhood: development and psychopathology. Third edition. Cengage learning

6. Sacco RL, Benjamin EJ, Broderick JP, Dyken M, Easton JD, Feinberg WM, Goldstein LB, Gorelick PB, Howard G, Kittner SJ, Manolio TA, Whisnant JP, Wolf PA (1997) Risk Factors. 
Stroke. 28(7):1507-1517. https://doi.org/10.1161/01.STR.28.7. 1507

7. Rentsch CT, Kidwai-Khan F, Tate JP, Park LS, King JT, Skanderson M, Hauser RG, Schultze A, Jarvis CI, Holodniy M, Lo Re V, Akgün KM, Crothers K, Taddei TH, Freiberg MS, Justice AC (2020) Patterns of COVID-19 testing and mortality by race and ethnicity among United States veterans: a nationwide cohort study. PLoS Med 17(9):e1003379. https://doi.org/10.1371/journal.pmed. 1003379

8. Mahase E (2020) Covid-19: Why are age and obesity risk factors for serious disease? BMJ. 371:m4130. https://doi.org/10.1136/bmj. $\mathrm{m} 4130$

9. Guo FR (2020) Smoking links to the severity of COVID-19: an update of a meta-analysis. J Med Virol 92(11):2304-2305. https:// doi.org/10.1002/jmv.25967

10. Zheng Z, Peng F, Xu B, Zhao J, Liu H, Peng J, Li Q, Jiang C, Zhou Y, Liu S, Ye C, Zhang P, Xing Y, Guo H, Tang W (2020) Risk factors of critical \& mortal COVID-19 cases: a systematic literature review and meta-analysis. J Infect 81(2):e16-e25. https://doi.org/ 10.1016/j.jinf.2020.04.021

11. Guo FR (2020) Active smoking is associated with severity of coronavirus disease 2019 (COVID-19): an update of a meta-analysis. Tob Induc Dis 18:37. https://doi.org/10.18332/tid/121915

12. Lippi G, Henry BM (2020) Active smoking is not associated with severity of coronavirus disease 2019 (COVID-19). Eur J Intern Med 75:107-108. https://doi.org/10.1016/j.ejim.2020.03.014

13. Vardavas CI, Nikitara K (2020) COVID-19 and smoking: a systematic review of the evidence. Tob Induc Dis 18:20. https://doi.org/10. 18332/tid/119324

14. Cheng Y, Cheng Y, Cheng $G$ et al (2005) ABO blood group and susceptibility to severe acute respiratory syndrome. JAMA. 293(12):1450-1451. https://doi.org/10.1001/jama.293.12.1450-c

15. Lebiush M, Rannon L, Kark JD (1981) The relationship between epidemic influenza $(\mathrm{A}(\mathrm{H} 1 \mathrm{~N} 1))$ and $\mathrm{ABO}$ blood group. J Hyg (Lond) 87(1):139-146

16. Mackenzie JS, Fimmel PJ (1978) The effect of ABO blood groups on the incidence of epidemic influenza and on the response to live attenuated and detergent split influenza virus vaccines. J Hyg (Lond) 80(1):21-30

17. Fan Q, Zhang W, Li B, Li D-J, Zhang J, Zhao F (2020) Association between ABO blood group system and COVID-19 susceptibility in Wuhan. Front Cell Infect Microbiol 10:404. https://doi.org/10. 3389/fcimb.2020.00404

18. Zhao J, Yang Y, Huang $\mathrm{H}$ et al (2020) Relationship between the $\mathrm{ABO}$ blood group and the COVID-19 susceptibility. Clin Infect Dis Off Publ Infect Dis Soc Am. https://doi.org/10.1093/cid/ciaa1150

19. Golinelli D, Boetto E, Maietti E, Fantini MP (2020) The association between ABO blood group and SARS-CoV-2 infection: A metaanalysis. PLoS One 15(9):e0239508. https://doi.org/10.1371/ journal.pone. 0239508

20. Wu B-B, Gu D-Z, Yu J-N, Yang J, Shen W-Q (2020) Association between $\mathrm{ABO}$ blood groups and COVID-19 infection, severity and demise: A systematic review and meta-analysis. Infect Genet Evol J Mol Epidemiol Evol Genet Infect Dis 84:104485. https://doi.org/ 10.1016/j.meegid.2020.104485

21. Wu Y, Feng Z, Li P, Yu Q (2020) Relationship between ABO blood group distribution and clinical characteristics in patients with COVID-19. Clin Chim Acta Int J Clin Chem 509:220-223. https:// doi.org/10.1016/j.cca.2020.06.026

22. Barnkob MB, Pottegård A, Støvring H, Haunstrup TM, Homburg K, Larsen R, Hansen MB, Titlestad K, Aagaard B, Møller BK, Barington T (2020) Reduced prevalence of SARS-CoV-2 infection in ABO blood group O. Blood Adv 4(20):4990-4993. https://doi. org/10.1182/bloodadvances.2020002657

23. Latz CA, DeCarlo C, Boitano L, Png CYM, Patell R, Conrad MF, Eagleton M, Dua A (2020) Blood type and outcomes in patients with COVID-19. Ann Hematol 99(9):2113-2118. https://doi.org/ 10.1007/s00277-020-04169-1

24. Zietz M, Zucker JE, Tatonetti NP (2020) Testing the association between blood type and COVID-19 infection, intubation, and death. medRxiv. https://doi.org/10.1101/2020.04.08.20058073

25. Padhi S, Suvankar S, Dash D, Panda VK, Pati A, Panigrahi J, Panda AK (2020) ABO blood group system is associated with COVID-19 mortality: an epidemiological investigation in the Indian population. Transfus Clin Biol 27(4):253-258. https://doi.org/10.1016/j. tracli.2020.08.009

26. Moher D, Liberati A, Tetzlaff J, Altman DG, PRISMA Group (2009) Preferred reporting items for systematic reviews and metaanalyses: the PRISMA statement. PLoS Med 6(7):e1000097. https://doi.org/10.1371/journal.pmed.1000097

27. Cooling L (2015) Blood groups in infection and host susceptibility. Clin Microbiol Rev 28(3):801-870. https://doi.org/10.1128/CMR. 00109-14

28. Severe acute respiratory syndrome. Centers for Disease Control and Prevention (CDC). https://www.cdc.gov/sars/index.html. Accessed November 30, 2020

29. Seasonal Influenza (Flu). Centers for Disease Control and Prevention (CDC). https://www.cdc.gov/flu/about/index.html

30. MEDLINE®: Description of the Database. https://www.nlm.nih. gov/bsd/medline.html. Accessed December 18, 2020

31. LitCovid. https://www.ncbi.nlm.nih.gov/research/coronavirus/. Accessed December 18, 2020

32. Principles of Epidemiology in Public Health Practice, Third Edition, An Introduction to Applied Epidemiology and Biostatistics. Centers for Disease Control and Prevention (CDC). https://www.cdc.gov/csels/dsepd/ss1978/lesson3/section5.html

33. Ray JG, Schull MJ, Vermeulen MJ, Park AL (2020) Association between $\mathrm{ABO}$ and Rh blood groups and SARS-CoV-2 infection or severe COVID-19 illness : a population-based cohort study. Ann Intern Med. https://doi.org/10.7326/M20-4511

34. Hoiland RL, Fergusson NA, Mitra AR, Griesdale DEG, Devine DV, Stukas S, Cooper J, Thiara S, Foster D, Chen LYC, Lee AYY, Conway EM, Wellington CL, Sekhon MS (2020) The association of $\mathrm{ABO}$ blood group with indices of disease severity and multiorgan dysfunction in COVID-19. Blood Adv 4(20):49814989. https://doi.org/10.1182/bloodadvances.2020002623

35. Taha SAH, MEM O, Abdoelkarim EAA et al (2020) Individuals with a Rh-positive but not Rh-negative blood group are more vulnerable to SARS-CoV-2 infection: demographics and trend study on COVID-19 cases in Sudan. New Microbes New Infect 38: 100763. https://doi.org/10.1016/j.nmni.2020.100763

36. Ellinghaus D, Degenhardt F, Bujanda L et al (2020) The ABO blood group locus and a chromosome 3 gene cluster associate with SARS-CoV-2 respiratory failure in an Italian-Spanish genomewide association analysis. medRxiv. https://doi.org/10.1101/2020. 05.31 .20114991

37. Trans-ethnic analysis reveals genetic and non-genetic associations with COVID-19 susceptibility and severity | medRxiv. https:// www.medrxiv.org/content/10.1101/2020.09.04.20188318v1. Accessed December 17, 2020

38. Silva-Filho JC, de Melo CGF, de Oliveira JL (2020) The influence of $\mathrm{ABO}$ blood groups on COVID-19 susceptibility and severity: a molecular hypothesis based on carbohydrate-carbohydrate interactions. Med Hypotheses 144:110155. https://doi.org/10.1016/j. mehy.2020.110155

39. Yan R, Zhang Y, Li Y, Xia L, Guo Y, Zhou Q (2020) Structural basis for the recognition of SARS-CoV-2 by full-length human ACE2. Science. 367(6485):1444-1448. https://doi.org/10.1126/ science.abb2762

40. Daniels G, Reid ME (2010) Blood groups: the past 50 years. Transfusion (Paris) 50(2):281-289. https://doi.org/10.1111/j. 1537-2995.2009.02456.x 
41. Cohen M, Hurtado-Ziola N, Varki A (2009) ABO blood group glycans modulate sialic acid recognition on erythrocytes. Blood. 114(17):3668-3676. https://doi.org/10.1182/blood-2009-06227041

42. Guillon P, Clément M, Sébille V, Rivain JG, Chou CF, RuvoënClouet N, le Pendu J (2008) Inhibition of the interaction between the SARS-CoV spike protein and its cellular receptor by anti-histoblood group antibodies. Glycobiology. 18(12):1085-1093. https:// doi.org/10.1093/glycob/cwn093

43. Arend P (2020) Why blood group A individuals are at risk whereas blood group $\mathrm{O}$ individuals are protected from SARS-CoV-2 (COVID-19) infection: a hypothesis regarding how the virus invades the human body via $\mathrm{ABO}(\mathrm{H})$ blood group-determining carbohydrates. Immunobiology:152027. https://doi.org/10.1016/j. imbio. 2020.152027
44. Hoffmann M, Kleine-Weber H, Krueger N, Mueller M (2020) The novel coronavirus 2019 (2019-nCoV) uses the SARS-coronavirus receptor ACE2 and the cellular protease TMPRSS2 for entry into target cells. bioRxiv (Query date: 2020-02-12 14:23:38). https:// www.biorxiv.org/content/10.1101/2020.01.31.929042v1.abstract

45. Antalis TM, Bugge TH, Wu Q (2011) Membrane-anchored serine proteases in health and disease. Prog Mol Biol Transl Sci 99:1-50. https://doi.org/10.1016/B978-0-12-385504-6.00001-4

46. Wang X, Dhindsa R, Povysil G et al (2020) Transcriptional Inhibition of host viral entry proteins as a therapeutic strategy for SARS-CoV-2. https://doi.org/10.20944/preprints202003.0360.v1

Publisher's note Springer Nature remains neutral with regard to jurisdictional claims in published maps and institutional affiliations. 